\title{
Diagnosis and Treatment of Discoid Meniscus
}

\author{
Jae-Gyoon Kim, MD, $\mathrm{PhD}^{1}$, Seung-Woo Han, $\mathrm{MD}^{1}$, and Dae-Hee Lee, $\mathrm{MD}, \mathrm{PhD}^{2}$ \\ ${ }^{1}$ Department of Orthopedic Surgery, Korea University Ansan Hospital, Ansan; ${ }^{2}$ Department of Orthopaedic Surgery, Samsung Medical Center, Sungkyunkwan \\ University School of Medicine, Seoul, Korea
}

\begin{abstract}
There is a greater incidence of discoid meniscus in Asian countries than in Western countries, and bilateral discoid menisci are also common. The discoid meniscus may be a congenital anomaly, and genetics or family history may play a role in the development of discoid menisci. Because the histology of discoid meniscus is different from that of normal meniscus, it is prone to tearing. Individuals with a discoid meniscus can be asymptomatic or symptomatic. Asymptomatic discoid menisci do not require treatment. However, operative treatment is necessary if there are symptoms. Total meniscectomy leads to an increased risk of osteoarthritis. Therefore, total meniscectomy is generally reserved for rare unsalvageable cases. Partial meniscectomy (saucerization) with preservation of a stable peripheral rim combined with or without peripheral repair is effective, and good short-, mid-, and long-term clinical results have been reported.
\end{abstract}

Keywords: Knee, Meniscus, Diagnosis, Treatment

\section{Introduction}

The discoid meniscus was first observed in a cadaver specimen by Young ${ }^{1)}$ in 1889 . For many years, the discoid meniscus was considered to be synonymous with snapping knee syndrome, which was first described by in $1936^{2}$. The incidence of discoid lateral meniscus is estimated to be $0.4 \%$ to $17 \%$, whereas the discoid medial meniscus is extremely rare $(0.1 \% \text { to } 0.3 \%)^{3-6)}$. It has been reported that about $20 \%$ of cases are bilateral ${ }^{5,78)}$. However, the true incidence and prevalence are unknown, given that many asymptomatic discoid menisci are incidentally discovered during surgery ${ }^{9}$. Some authors have reported that magnetic resonance imaging (MRI) or arthroscopic evaluation reveals higher rates (79\% to $97 \%$ ) of bilateral discoid lateral meniscus in patients

Received September 5, 2016; Revised October 23, 2016;

Accepted October 24, 2016

Correspondence to: Dae-Hee Lee, MD, PhD

Department of Orthopaedic Surgery, Samsung Medical Center, Sungkyunkwan University School of Medicine, 81 Irwon-ro, Gangnamgu, Seoul 06351, Korea

Tel: +82-2-3410-3509, Fax: +82-2-3410-0061

E-mail: eoak22@empal.com

This is an Open Access article distributed under the terms of the Creative Commons Attribution Non-Commercial License (http://creativecommons.org/licenses/by-nc/4.0/) which permits unrestricted non-commercial use, distribution, and reproduction in any medium, provided the original work is properly cited. presenting with symptomatic unilateral discoid lateral meniscus $^{10,11}$. There is a greater incidence of discoid meniscus in Asian countries than in Western countries ${ }^{12-14)}$. Fukuta et al. ${ }^{12)}$ reported an incidence of $13 \%$ in Japan, Kim et al. ${ }^{13)}$ observed an incidence of $10.6 \%$ in Korea, and Rao et al. ${ }^{14)}$ noted an incidence of $5.8 \%$ in India. In contrast, Jordan ${ }^{15)}$ described an incidence of 3\% to $5 \%$ in the United States. This review summarizes the current knowledge on the diagnosis and treatment of discoid meniscus.

\section{Embryology and Anatomy}

Smillie ${ }^{16)}$ suggested that the discoid meniscus is congenital. The discoid shape is an intermediate stage during fetal development, and final discoid morphology results from absorption failure of the central part of the menisci. However, the discoid shape has not yet been identified in anatomical studies on either human or animal embryos ${ }^{17,18}$. The discoid meniscus may indeed be a congenital anomaly ${ }^{9,17)}$, and genetic or familial factors may play a role in the development of discoid menisci, ${ }^{8,19}$. Some authors have reported bilateral discoid menisci in identical female twins ${ }^{20)}$ or in a family of three brothers and sisters ${ }^{20,21}$. The histology and ultrastructure of discoid meniscus is different from that of normal meniscus. The discoid meniscus is characterized by decreased collagen fibers and loss of normal collagen orientation, and intrameniscal mucoid degeneration is also common ${ }^{9,22}$. 


\section{Kim et al. Diagnosis and Treatment of Discoid Meniscus}

Papadopoulos et al. ${ }^{23)}$ documented significant disorganization of the circular collagen network and a heterogeneous course of the circumferentially arranged collagen fibers in discoid meniscus structure. They also proposed that the discoid lesion is a structural rather than a morphological variant. In addition to structural abnormality, the increased thickness and abnormal vascularity of the discoid meniscus makes it prone to tearing ${ }^{17)}$. Morphological changes may also occur to compensate for an abnormally unstable meniscus during development ${ }^{18)}$. Recently, some authors have reported regeneration after partial meniscectomy of the discoid meniscus ${ }^{24-26)}$. This regeneration supports the possibility that the discoid meniscus arises through variant morphogenesis ${ }^{26)}$.

\section{Classification}

Watanabe et al. ${ }^{27)}$ classified the discoid menisci as complete, incomplete, and Wrisberg types, depending on the presence or absence of a normal posterior attachment and the degree of tibial plateau coverage (Fig. 1). The complete type refers to the discshaped meniscus that completely covers the lateral tibial plateau and has a normal posterior attachment. The incomplete type has a semilunar shape and a normal posterior attachment, but it covers less than $80 \%$ of the lateral tibial plateau ${ }^{9,27)}$. The Wrisberg type is more normally shaped than the complete and incomplete types, but it lacks the usual posterior meniscal attachments (coronary ligament), and only the Wrisberg ligament connects the posterior horn of the lateral meniscus. Due to the hypermobility of the lateral meniscus in this type, the meniscus is subject to displacement in knee flexion and extension, which is postulated to cause the classic snapping knee syndrome ${ }^{9)}$. Although this classification is commonly used, its usefulness for surgical decision making is doubtful ${ }^{28)}$. Klingele et al. ${ }^{29)}$ described patterns of peripheral rim instability in discoid menisci. They defined instability as evidence of hypermobility and peripheral detachment of the remnant meniscus in arthroscopic assessment. They further differentiated the unstable menisci of both the complete and incomplete types according to the location of instability (anterior, middle, and posterior horn $)^{30)}$. Ahn et al. ${ }^{31)}$ proposed an MRI classification based on the presence or direction of meniscal shift: no shift, anterocentral shift, posterocentral shift, and central shift. They reported that shift-type knees had more peripheral tears than no-shift knees. They also classified discoid lateral meniscus tears based on arthroscopic evaluation of both peripheral rim stability and tear site: 1) meniscocapsular junction, anterior horn type, 2) meniscocapsular junction, posterior horn type, and 3) posterolateral corner loss type (Fig. 2) ${ }^{32)}$. These MRI and arthroscopic classifications provide more information to surgeons on appropriate treatment methods for discoid lateral menisci.

\section{Clinical Features}

Individuals with a discoid meniscus can be asymptomatic ${ }^{5)}$. If there is a tear or instability, symptoms typically develop in discoid meniscus ${ }^{28)}$. However, a click or pain can develop even in the absence of a tear or instability ${ }^{33)}$. Symptoms of discoid meniscus include insidious popping or snapping without a traumatic origin, which is associated with pain, giving way, effusion, quadriceps atrophy, limited range of motion, and clicking or locking ${ }^{28,34)}$.
A

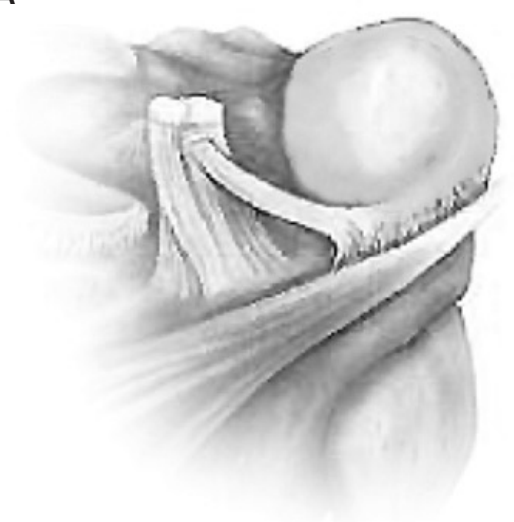

B

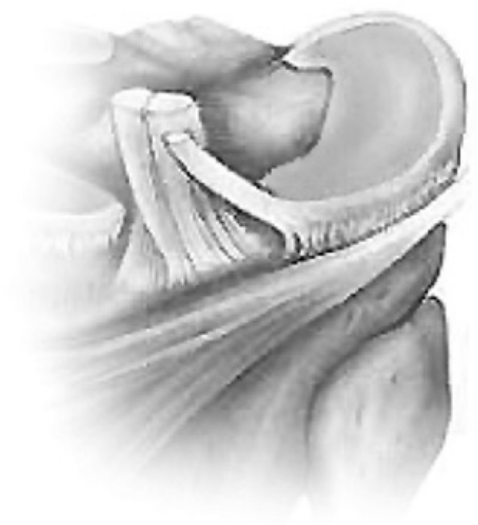

C

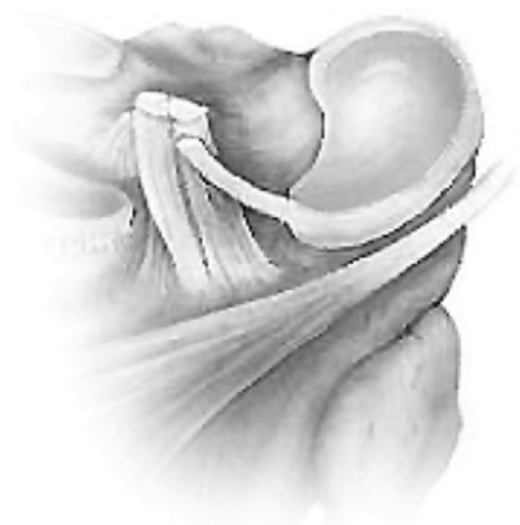

Fig. 1. Watanabe classification. (A) The complete type is the disc-shaped meniscus that completely covers the lateral tibial plateau and has a normal posterior attachment. (B) The incomplete type has a semilunar shape and normal posterior attachment, but it covers less than $80 \%$ of the lateral tibial plateau. (C) The Wrisberg type is more normally shaped compared to the complete or incomplete type of discoid meniscus, but it lacks the usual posterior meniscal attachments (coronary ligament), and only the Wrisberg ligament connects the posterior horn of the lateral meniscus. 

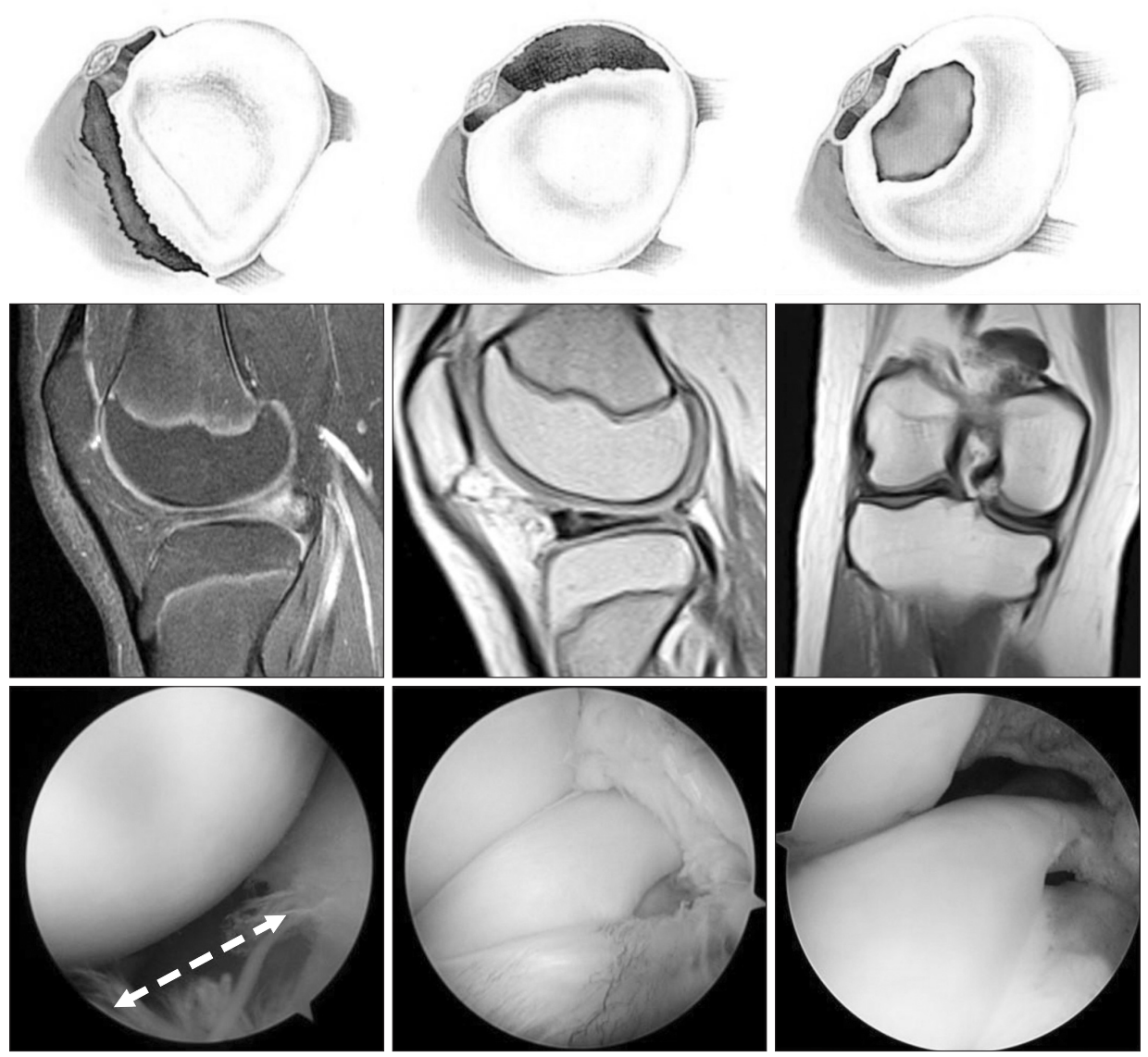

Fig. 2. Magnetic resonance imaging findings and arthroscopic views of the discoid meniscus according to the corresponding tear pattern. A peripheral tear refers to a longitudinal tear in the meniscocapsular junction area, anterior horn (posterocentral shift, left column), and posterior horn (anterocentral shift, middle column). The white dotted arrow (bottom, left column) shows the wide gap between the anterolateral border of the meniscus and the joint capsule. Posterolateral corner loss refers to the absence of the posterolateral portion of the discoid meniscus due to degenerative tears around the popliteal hiatus (central shift).
Snapping knee syndrome, in which a clunk is heard at the end of flexion, is usually related to an unstable meniscus variant, such as the Wrisberg type ${ }^{35,36)}$. In very young children (range, 3 to 4 years), snapping is often asymptomatic, whereas older children (range, 8 to 10 years) more commonly experience pain with activity $^{37)}$. In addition, the older child may present with more acute symptoms than younger children ${ }^{28)}$. The most common tear pattern of the discoid meniscus is a horizontal tear ${ }^{30,38-40)}$. Repetitive microtrauma to the abnormal collagen arrangement is thought to cause horizontal tears after mucoid degeneration, ${ }^{9,41)}$.

\section{Diagnosis}

Radiographs are often normal in patients with a discoid meniscus; however, they may reveal some radiologic features of discoid meniscus, such as widening of the lateral joint space, a squared-off appearance of the lateral femoral condyle, cupping of the lateral tibial plateau, elevation of the fibular head, and tibial eminence flattening ${ }^{9,14,19)}$. On MRI, a discoid meniscus can be diagnosed when the ratio of the minimal meniscal width to the maximal tibial width is more than $20 \%$ on the coronal image, and the ratio of sum of the width of both lateral horns to the maximal meniscal diameter on the sagittal image is more than $75 \%{ }^{42}$. Araki et al. ${ }^{43)}$ have proposed that the discoid meniscus is present when the meniscal width is over $15 \mathrm{~mm}$ on the coronal slice. Continuity of the meniscus between the anterior and posterior horns on three or more 5-mm thick consecutive sagittal slices demonstrates the presence of a discoid meniscus ${ }^{6}$. An abnormal, thickened, bow-tie appearance of the meniscus is suggestive of discoid meniscus ${ }^{28)}$. In the Wrisberg variant, an MRI scan may show subtle anterior subluxation of the posterior horn of the lateral meniscus or high T2-weighted signal intensity, simulating a peripheral tear ${ }^{35)}$. However, some authors have reported low sensitivity in detecting the lateral discoid meniscus in children and have suggested that MRI does not provide enhanced diagnostic utility over clinical examination ${ }^{44)}$ because checking the stability of a discoid meniscus on an MRI scan is difficult, and some incomplete discoid menisci often look normal ${ }^{9,19)}$. Nonetheless, MRI is useful in detecting the presence of meniscus tear and a shift of the meniscus. This information can aid the surgeon in determining the appropriate surgical technique, such as saucerization or repair ${ }^{31,45)}$. Diagnostic arthroscopy may be needed to con- 
firm the diagnosis of discoid meniscus in a symptomatic patient with instability or with the Wrisberg variant, showing a normal shape and MRI appearance ${ }^{5}$. On physical examination, patients show joint line tenderness, effusion, joint line bulging, and even a positive McMurray test ${ }^{7,15}$. The accuracy of physical examination ranges from $29 \%$ to $93 \%$ and varies according to the examiner's experience and knowledge of this anomaly ${ }^{4,46)}$.

\section{Treatment}

The factors determining treatment include the type of discoid meniscus, concomitant symptoms, duration of symptoms, and age $^{47}$. Most cases of discoid meniscus remain asymptomatic and do not require treatment, even when snapping is present ${ }^{9,47-49)}$ because the knee may have adapted to the discoid anatomy and continues to function well ${ }^{39)}$. However, there is some debate about the need for treatment in cases of asymptomatic, stable discoid meniscus found incidentally during evaluation or treatment of some other knee conditions ${ }^{28)}$. If there are symptoms such as pain, locking, swelling, giving way, or instability, it is necessary to operate $^{28}$. In the case of a symptomatic but stable meniscus, some authors have suggested total meniscectomy due to the risk of intrinsic abnormalities in the remaining meniscal tissue ${ }^{50}$. However, many studies have suggested that total meniscectomy leads to a high risk of osteoarthritis ${ }^{9,51,52)}$. Total meniscectomy is generally avoided in children, except in rare cases in which the entire meniscus is deemed to be unsalvageable ${ }^{9}$. Partial meniscectomy (saucerization) with preservation of a stable peripheral rim, with or without peripheral repair, is effective and has been recommended by many authors ${ }^{7,32,48}$. For the unstable type, repair of the posterior tibial detachment is important to eliminate the risk of osteoarthritis after total meniscectomy ${ }^{3,15)}$.

Arthroscopic partial meniscectomy (saucerization) is most commonly recommended. This treatment attempts to change the meniscus to a more normal shape and size ${ }^{3,9,19,30,32,38,40,48,49)}$. In cases of peripheral tear in the vascular zone, arthroscopic meniscal repair can be done with saucerization according to advancement of the repair technique ${ }^{32,48}$. The goal of saucerization is to create a stable and functional meniscus that will provide adequate shock absorption without retearing ${ }^{9}$. Many authors have recommended that at least $6 \mathrm{~mm}$ to $8 \mathrm{~mm}$ from the periphery should remain ${ }^{8,48,49}$; however, larger meniscal remnants after saucerization have been associated with increased re-tear rates ${ }^{39)}$.

After partial meniscectomy (saucerization) and/or repair of a discoid meniscus, the remaining discoid meniscus is more vulnerable to tearing than the normal meniscus because the cartilage remains thickened due to the abnormal discoid meniscus ${ }^{19)}$. A complication unique to discoid meniscus surgery is osteochondritis dissecans (OCD) of the lateral femoral condyle, which can occur after total or partial meniscetomy of the discoid lateral meniscus. Repeated impaction in the immature chondral structure after resection of the discoid meniscus might predispose to the development of OCD in the lateral femoral condyle ${ }^{53,54}$. In addition, the change of alignment to valgus after resection of a thick discoid meniscus can lead to concentrated stress on the lateral femoral condyle $e^{55)}$.

\section{Clinical Outcomes}

Many authors have reported good clinical results after partial meniscectomy with or without meniscus repair over short-, mid-, and long-term follow ups ${ }^{30,32,49,50,54,56-59)}$ (Table 1). Ahn et al. ${ }^{32)}$ reported in their study with a minimum 2-year follow-up (mean, 51 months) that arthroscopic partial meniscectomy with peripheral repair was effective for treating symptomatic discoid lateral menisci. In a short-term follow-up study (mean, 37.4 months), Good et al. ${ }^{30)}$ also reported on the efficacy of arthroscopic saucerization with repair. Ogut et al. ${ }^{57)}$ reported on 10 knees with complete discoid lateral menisci that underwent arthroscopic partial meniscectomy; after a mean follow-up of 4.5 years, 9 cases had excellent results, and there was no evidence of degenerative changes on radiographic examination. In a study with a 5-year follow-up, Atay et al. ${ }^{49)}$ reported that $85 \%$ of cases showed good or excellent results after partial meniscectomy; however, femoral condyle flattening occurred in a significant percentage. In a study with a 5.5-year follow-up, Aichroth et al. ${ }^{50)}$ reported that $84 \%$ of cases showed excellent or good results after total or partial meniscectomy. Recently, Yoo et al ${ }^{54)}$ found that Lysholm scores increased from a mean of 70.0 to a mean of 91.6 at the final follow-up irrespective of the meniscectomy method (partial or subtotal) after a mean of 4.7 years. Ahn et al. ${ }^{59)}$ reported in their long-term followup study (mean, 10.1 years) that $94 \%$ of patients had excellent or good clinical results; however, progressive degenerative changes appeared in $40 \%$ of patients. Some authors have described good clinical results of meniscal allograft transplantation after total meniscectomy for a torn discoid lateral meniscus ${ }^{60)}$.

\section{Prognostic Factors}

Some authors have suggested that younger patients are more likely to achieve better results after partial or total meniscecto$m y^{54,61}$. In addition, removing a greater amount of meniscus has 
Table 1. Clinical Results of Lateral Discoid Meniscus Treatment

\begin{tabular}{|c|c|c|c|c|c|c|}
\hline Author & $\begin{array}{l}\text { No. of } \\
\text { cases } \\
\text { (knee) }\end{array}$ & $\begin{array}{l}\text { Mean } \\
\text { age } \\
(\mathrm{yr})\end{array}$ & $\begin{array}{l}\text { Mean } \\
\text { F/U } \\
(y r)\end{array}$ & Discoid meniscus type & Treatment & Results \\
\hline $\begin{array}{l}\text { Good } \\
\text { et al. }^{30)}\end{array}$ & $21(23)$ & 10.1 & 3.2 & $\begin{array}{l}\text { Complete, incomplete, and } \\
\text { unstable types (anterior horn } \\
\text { instability, posterior horn } \\
\text { instability, and combined } \\
\text { anterior and posterior } \\
\text { instability) }\end{array}$ & $\begin{array}{l}\text { Arthroscopic partial central } \\
\text { meniscectomy with } \\
\text { peripheral suture repair } \\
(\mathrm{n}=22) \\
\text { Arthroscopic total } \\
\text { meniscectomy }(\mathrm{n}=1)\end{array}$ & $\begin{array}{l}\text { All patients had full knee flexion } \\
\text { Residual knee pain }(n=3) \\
\text { Intermittent mechanical symptoms }(n=4) \\
\text { Partially limited activity }(n=2)\end{array}$ \\
\hline $\begin{array}{l}\text { Ahn } \\
\text { et al. }\end{array}$ & $23(28)$ & 9.0 & 4.2 & $\begin{array}{l}\text { Discoid meniscus with } \\
\text { peripheral tear }\end{array}$ & $\begin{array}{l}\text { Arthroscopic partial central } \\
\text { meniscectomy with } \\
\text { peripheral suture repair }\end{array}$ & $\begin{array}{l}\text { All patients returned to their previous level of } \\
\text { activity } \\
\text { No reoperation was required } \\
\text { Improvement in Lysholm and HSS scores }\end{array}$ \\
\hline $\begin{array}{l}\text { Atay } \\
\text { et al. }^{49)}\end{array}$ & $33(34)$ & 19.8 & 5.6 & $\begin{array}{l}\text { Complete, incomplete, and } \\
\text { Wrisberg types }\end{array}$ & $\begin{array}{l}\text { Arthroscopic partial } \\
\text { meniscectomy }\end{array}$ & $\begin{array}{l}\text { Ikeuchi grading: excellent (39\%), good ( } 46 \%) \text {, } \\
\text { fair }(15 \%) \text {, and poor }(0 \%)\end{array}$ \\
\hline $\begin{array}{l}\text { Aichroth } \\
\text { et al. }^{50)}\end{array}$ & $52(62)$ & 10.5 & 5.5 & Torn $(n=36)$, intact $(n=26)$ & $\begin{array}{l}\text { Open total meniscectomy } \\
(\mathrm{n}=48) \\
\text { Arthroscopic partial } \\
\text { meniscectomy }(\mathrm{n}=6) \\
\text { Left alone }(\mathrm{n}=8)\end{array}$ & $\begin{array}{l}\text { Ikeuchi grading: excellent (37\%), good ( } 47 \%) \text {, } \\
\text { fair }(16 \%) \text {, and poor }(0 \%) \\
\text { No radiographic joint space narrowing }\end{array}$ \\
\hline $\begin{array}{l}\text { Yoo } \\
\text { et al. }{ }^{54)}\end{array}$ & $86(100)$ & 10.7 & 4.7 & $\begin{array}{l}\text { Complete, incomplete, and } \\
\text { Wrisberg types }\end{array}$ & $\begin{array}{l}\text { Partial meniscectomy with/ } \\
\text { without suture repair } \\
\text { Subtotal meniscectomy }\end{array}$ & $\begin{array}{l}\text { Lysholm score improved regardless of } \\
\text { treatment method } \\
\text { Early degenerative change }(\mathrm{n}=11) \\
\text { Younger age ( }<10 \text { years) was a positive } \\
\text { prognostic factor }\end{array}$ \\
\hline $\begin{array}{l}\text { Ogut } \\
\text { et al. }\end{array}$ & 11 knees & 11.5 & 4.5 & $\begin{array}{l}\text { Complete }(n=10) \text {, with } \\
\text { tear }(n=8)\end{array}$ & $\begin{array}{l}\text { Arthroscopic partial } \\
\text { meniscectomy }\end{array}$ & $\begin{array}{l}\text { Ikeuchi grading: excellent }(n=9) \text { and good } \\
(n=2) \\
\text { No degenerative changes }\end{array}$ \\
\hline $\begin{array}{l}\text { Ahn } \\
\text { et al. }^{59)}\end{array}$ & $38(48)$ & 9.9 & 10.1 & $\begin{array}{l}\text { MRI classification: no shift } \\
(63 \%) \text {, anterocentral shift (8\%), } \\
\text { posterocentral shift (13\%), and } \\
\text { central shift }(17 \%)\end{array}$ & $\begin{array}{l}\text { Arthroscopic partial } \\
\text { meniscectomy with/ } \\
\text { without repair } \\
\text { Subtotal meniscectomy }\end{array}$ & $\begin{array}{l}\text { Ikeuchi grading: excellent and good (94\%) } \\
\text { Median Tegner scale: } 7 \\
\text { Improvement of Lysholm score } \\
\text { Radiographic degenerative change }(39.5 \%) \\
\text { The subtotal meniscectomy group showed } \\
\text { 87.5\% of degenerative changes }\end{array}$ \\
\hline
\end{tabular}

F/U: follow-up, HSS: Hospital for Special Surgery, MRI: magnetic resonance imaging.

been associated with increased contact pressure on the cartilage and thus an increased risk of cartilage degeneration ${ }^{58)}$. Several studies have found that the results of partial meniscectomy are better than those of total meniscectomy both clinically and radiologically ${ }^{58,59,62)}$. Kim et al. ${ }^{58)}$ assessed the mid-term clinical and radiological outcomes of discoid lateral meniscus treated by partial or total meniscectomy and found that partial meniscectomy was associated with better radiographic results after a 5-year follow-up. In a long-term follow-up study (mean, 10.1 years), Ahn et al. ${ }^{59)}$ also reported that subtotal meniscectomy was associated with increased degenerative changes compared with partial meniscectomy with or without repair. Lee et al. ${ }^{62)}$ found better radiological results after partial meniscectomy than subtotal/total meniscectomy in a mid-term follow-up, but clinical results did not differ significantly between treatment types.

\section{Conclusions}

The incidence of discoid meniscus is greater in Asian countries than in Western countries, and bilateral discoid menisci are common. The discoid meniscus may be a congenital anomaly, and the structure of discoid meniscus is different from that of normal meniscus. Therefore, it is more prone to tearing than a normal meniscus. Asymptomatic discoid menisci do not require 
treatment. However, if there are symptoms, operative treatment is necessary. Since total meniscectomy leads to a high risk of osteoarthritis, total meniscectomy should be avoided except for unsalvageable cases. Partial meniscectomy (saucerization) with preservation of a stable peripheral rim combined with or without peripheral repair is recommended, and good clinical results have been reported.

\section{Conflict of Interest}

No potential conflict of interest relevant to this article was reported.

\section{References}

1. Young RB. The external semilunar cartilage as a complete disc. In: Cleland J, Mackay JY, Young RB, eds. Memoirs and memoranda in anatomy. London: Williams and Norgate; 1889. p179.

2. Middleton DS. Congenital disc-shaped lateral meniscus with snapping knee. Br J Surg. 1936;24:246-55.

3. Ikeuchi H. Arthroscopic treatment of the discoid lateral meniscus. Technique and long-term results. Clin Orthop Relat Res. 1982;(167):19-28.

4. Kini SG, Walker P, Bruce W. Bilateral symptomatic discoid medial meniscus of the knee: a case report and review of literature. Arch Trauma Res. 2015;4:e27115.

5. Kelly BT, Green DW. Discoid lateral meniscus in children. Curr Opin Pediatr. 2002;14:54-61.

6. Silverman JM, Mink JH, Deutsch AL. Discoid menisci of the knee: MR imaging appearance. Radiology. 1989;173:351-4.

7. Fleissner PR, Eilert RE. Discoid lateral meniscus. Am J Knee Surg. 1999;12:125-31.

8. Yaniv M, Blumberg N. The discoid meniscus. J Child Orthop. 2007;1:89-96.

9. Kramer DE, Micheli LJ. Meniscal tears and discoid meniscus in children: diagnosis and treatment. J Am Acad Orthop Surg. 2009;17:698-707.

10. Ahn JH, Lee SH, Yoo JC, Lee HJ, Lee JS. Bilateral discoid lateral meniscus in knees: evaluation of the contralateral knee in patients with symptomatic discoid lateral meniscus. Arthroscopy. 2010;26:1348-56.

11. Bae JH, Lim HC, Hwang DH, Song JK, Byun JS, Nha KW. Incidence of bilateral discoid lateral meniscus in an Asian population: an arthroscopic assessment of contralateral knees. Arthroscopy. 2012;28:936-41.
12. Fukuta S, Masaki K, Korai F. Prevalence of abnormal findings in magnetic resonance images of asymptomatic knees. J Orthop Sci. 2002;7:287-91.

13. Kim SJ, Lee YT, Kim DW. Intraarticular anatomic variants associated with discoid meniscus in Koreans. Clin Orthop Relat Res. 1998;(356):202-7.

14. Rao PS, Rao SK, Paul R. Clinical, radiologic, and arthroscopic assessment of discoid lateral meniscus. Arthroscopy. 2001; 17:275-7.

15. Jordan MR. Lateral meniscal variants: evaluation and treatment. J Am Acad Orthop Surg. 1996;4:191-200.

16. Smillie IS. The congenital discoid meniscus. J Bone Joint Surg Br. 1948;30:671-82.

17. Clark CR, Ogden JA. Development of the menisci of the human knee joint. Morphological changes and their potential role in childhood meniscal injury. J Bone Joint Surg Am. 1983;65:538-47.

18. Kaplan EB. Discoid lateral meniscus of the knee joint; nature, mechanism, and operative treatment. J Bone Joint Surg Am. 1957;39:77-87.

19. Hart ES, Kalra KP, Grottkau BE, Albright M, Shannon EG. Discoid lateral meniscus in children. Orthop Nurs. 2008; 27:174-9.

20. Gebhardt MC, Rosenthal RK. Bilateral lateral discoid meniscus in identical twins. J Bone Joint Surg Am. 1979;61:1110-1.

21. de Lambilly C, Pascarel X, Chauvet JF, Marle JL, Honton JL. External discoid menisci: apropos of a familial series of 6 cases. Rev Chir Orthop Reparatrice Appar Mot. 1991;77:35961.

22. Atay OA, Pekmezci M, Doral MN, Sargon MF, Ayvaz M, Johnson DL. Discoid meniscus: an ultrastructural study with transmission electron microscopy. Am J Sports Med. 2007; 35:475-8.

23. Papadopoulos A, Kirkos JM, Kapetanos GA. Histomorphologic study of discoid meniscus. Arthroscopy. 2009;25:262-8.

24. Stein MI, Gaskins RB 3rd, Nalley CC, Nofsinger C. Regeneration of a discoid meniscus after arthroscopic saucerization. Am J Orthop (Belle Mead NJ). 2013;42:E5-8.

25. Soejima T, Kanazawa T, Tabuchi K, Noguchi K, Inoue T, Murakami H. Regeneration of ring-shaped lateral meniscus after partial resection of discoid meniscus with anterior cruciate ligament reconstruction. Int J Surg Case Rep. 2013;4: 1093-6.

26. Bisicchia S, Tudisco C. Re-growth of an incomplete discoid lateral meniscus after arthroscopic partial resection in an 11 year-old boy: a case report. BMC Musculoskelet Disord. 
2013;14:285.

27. Watanabe M, Takeda S, Ikeuchi H. Atlas of arthroscopy. 3rd ed. Tokyo: Igaku-Shoin; 1979. p75-130.

28. Kushare I, Klingele K, Samora W. Discoid meniscus: diagnosis and management. Orthop Clin North Am. 2015;46:53340.

29. Klingele KE, Kocher MS, Hresko MT, Gerbino P, Micheli LJ. Discoid lateral meniscus: prevalence of peripheral rim instability. J Pediatr Orthop. 2004;24:79-82.

30. Good CR, Green DW, Griffith MH, Valen AW, Widmann RF, Rodeo SA. Arthroscopic treatment of symptomatic discoid meniscus in children: classification, technique, and results. Arthroscopy. 2007;23:157-63.

31. Ahn JH, Lee YS, Ha HC, Shim JS, Lim KS. A novel magnetic resonance imaging classification of discoid lateral meniscus based on peripheral attachment. Am J Sports Med. 2009;37: 1564-9.

32. Ahn JH, Lee SH, Yoo JC, Lee YS, Ha HC. Arthroscopic partial meniscectomy with repair of the peripheral tear for symptomatic discoid lateral meniscus in children: results of minimum 2 years of follow-up. Arthroscopy. 2008;24:888 98.

33. Francavilla ML, Restrepo R, Zamora KW, Sarode V, Swirsky SM, Mintz D. Meniscal pathology in children: differences and similarities with the adult meniscus. Pediatr Radiol. 2014;44:910-25.

34. Mutlu S, Mutlu H, Mutlu B, Guler O, Duymus TM. Symptoms of discoid lateral menisci. J Orthop. 2014;11:180-2.

35. Singh K, Helms CA, Jacobs MT, Higgins LD. MRI appearance of Wrisberg variant of discoid lateral meniscus. AJR Am J Roentgenol. 2006;187:384-7.

36. Wong T, Wang CJ. Functional analysis on the treatment of torn discoid lateral meniscus. Knee. 2011;18:369-72.

37. Dickhaut SC, DeLee JC. The discoid lateral-meniscus syndrome. J Bone Joint Surg Am. 1982;64:1068-73.

38. Bellisari G, Samora W, Klingele K. Meniscus tears in children. Sports Med Arthrosc. 2011;19:50-5.

39. Hayashi LK, Yamaga H, Ida K, Miura T. Arthroscopic meniscectomy for discoid lateral meniscus in children. J Bone Joint Surg Am. 1988;70:1495-500.

40. Kocher MS, Klingele K, Rassman SO. Meniscal disorders: normal, discoid, and cysts. Orthop Clin North Am. 2003;34: 329-40.

41. Smith CF, Van Dyk GE, Jurgutis J, Vangsness CT Jr. Cautious surgery for discoid menisci. Am J Knee Surg. 1999;12:25-8.

42. Samoto N, Kozuma M, Tokuhisa T, Kobayashi K. Diagno- sis of discoid lateral meniscus of the knee on MR imaging. Magn Reson Imaging. 2002;20:59-64.

43. Araki Y, Ashikaga R, Fujii K, Ishida O, Hamada M, Ueda J, Tsukaguchi I. MR imaging of meniscal tears with discoid lateral meniscus. Eur J Radiol. 1998;27:153-60.

44. Kocher MS, DiCanzio J, Zurakowski D, Micheli LJ. Diagnostic performance of clinical examination and selective magnetic resonance imaging in the evaluation of intraarticular knee disorders in children and adolescents. Am J Sports Med. 2001;29:292-6.

45. Yilgor C, Atay OA, Ergen B, Doral MN. Comparison of magnetic resonance imaging findings with arthroscopic findings in discoid meniscus. Knee Surg Sports Traumatol Arthrosc. 2014;22:268-73.

46. Stanitski CL. Correlation of arthroscopic and clinical examinations with magnetic resonance imaging findings of injured knees in children and adolescents. Am J Sports Med. 1998;26:2-6.

47. Sun Y, Jiang Q. Review of discoid meniscus. Orthop Surg. 2011;3:219-23.

48. Adachi N, Ochi M, Uchio Y, Kuriwaka M, Shinomiya R. Torn discoid lateral meniscus treated using partial central meniscectomy and suture of the peripheral tear. Arthroscopy. 2004;20:536-42.

49. Atay OA, Doral MN, Leblebicioglu G, Tetik O, Aydingoz U. Management of discoid lateral meniscus tears: observations in 34 knees. Arthroscopy. 2003;19:346-52.

50. Aichroth PM, Patel DV, Marx CL. Congenital discoid lateral meniscus in children: a follow-up study and evolution of management. J Bone Joint Surg Br. 1991;73:932-6.

51. Fairbank TJ. Knee joint changes after meniscectomy. J Bone Joint Surg Br. 1948;30:664-70.

52. Raber DA, Friederich NF, Hefti F. Discoid lateral meniscus in children. Long-term follow-up after total meniscectomy. J Bone Joint Surg Am. 1998;80:1579-86.

53. Stanitski CL, Bee J. Juvenile osteochondritis dissecans of the lateral femoral condyle after lateral discoid meniscal surgery. Am J Sports Med. 2004;32:797-801.

54. Yoo WJ, Jang WY, Park MS, Chung CY, Cheon JE, Cho TJ, Choi IH. Arthroscopic treatment for symptomatic discoid meniscus in children: midterm outcomes and prognostic factors. Arthroscopy. 2015;31:2327-34.

55. Hashimoto Y, Yoshida G, Tomihara T, Matsuura T, Satake S, Kaneda K, Shimada N. Bilateral osteochondritis dissecans of the lateral femoral condyle following bilateral total removal of lateral discoid meniscus: a case report. Arch Orthop Trau- 
ma Surg. 2008;128:1265-8.

56. Lee CH, Song IS, Jang SW, Cha HE. Results of arthroscopic partial meniscectomy for lateral discoid meniscus tears associated with new technique. Knee Surg Relat Res. 2013;25:30-5.

57. Ogut T, Kesmezacar H, Akgun I, Cansu E. Arthroscopic meniscectomy for discoid lateral meniscus in children and adolescents: 4.5 year follow-up. J Pediatr Orthop B. 2003;12: 390-7.

58. Kim SJ, Chun YM, Jeong JH, Ryu SW, Oh KS, Lubis AM. Effects of arthroscopic meniscectomy on the long-term prognosis for the discoid lateral meniscus. Knee Surg Sports Traumatol Arthrosc. 2007;15:1315-20.

59. Ahn JH, Kim KI, Wang JH, Jeon JW, Cho YC, Lee SH. Long- term results of arthroscopic reshaping for symptomatic discoid lateral meniscus in children. Arthroscopy. 2015;31:86773.

60. Kim JM, Bin SI. Meniscal allograft transplantation after total meniscectomy of torn discoid lateral meniscus. Arthroscopy. 2006;22:1344-50.

61. Okazaki K, Miura H, Matsuda S, Hashizume M, Iwamoto Y. Arthroscopic resection of the discoid lateral meniscus: longterm follow-up for 16 years. Arthroscopy. 2006;22:967-71.

62. Lee DH, Kim TH, Kim JM, Bin SI. Results of subtotal/total or partial meniscectomy for discoid lateral meniscus in children. Arthroscopy. 2009;25:496-503. 